\title{
Proprietary rights to research
}

\section{The rules that say when authors should make research materials available to others cannot be hard and fast. But release should be the rule, not the exception.}

To what extent are researchers who have announced some discovery of importance beholden to colleagues (and competitors) in other laboratories to provide research materials necessary for the replication of the work reported? This is the question vividly raised by the exchange of letters appearing on pages 21 and 22 of this issue. The issues raised are ancient, common and of a personal character.

The circumstances are these. Two years ago, Gusella and his associates described the isolation of a genetic probe for a part of the human chromosome 4 lying so close to the unidentified gene responsible for Huntington's chorea that it seemed as if it might be a diagnostic agent for the disease. Two years ago, the technique by which this had been done was relatively new. It rests on the facility for chopping chromosomal DNA into pieces of different lengths by the use of restriction enzymes. Gusella's finding of a putative genetic probe for Huntington's chorea was one of the first successes of this kind; in the interval, specific probes for other genetic diseases (Duchenne muscular dystrophy and cystic fibrosis, for example) have come to light.

The nature of the technique is crucial to an understanding of the dispute between Gusella and a group in Oxford, which has been itching to get its hands on the Huntington's probe during the past two years. Not all the DNA in the human (or any other genome) is meaningful. Some consists of sequences of nucleic acids that encode essential protein molecules, but some of it is a "nonsense" DNA in the extreme sense; it may consist only of mindless stretches of apparently meaningless repeating units. Between these extremes, there are stretches of DNA whose placing and character play essential parts in the regulation of gene expression. Still others appear to have a function no more specific than that of holding together essential pieces of DNA at the correct spacing, and can thus continue to function even if quite substantial variations of the nucleotide sequence occur.

Because restriction enzymes cut DNA molecules only at places where the nucleotide sequence is that specific to their own function, variations among the genome of individuals will, now and again, yield places where the genome may, or may not, be cut by a particular enzyme. The upshot may be a variation between one person's genome and another's, revealed by the occurrence of differently sized fragments. Experience in the past few years has indeed shown that these differences are inheritable. This polymorphism is exactly analogous to that in which functional proteins such as the globin of haemoglobin may vary from one person to another and, given parallel inheritance from two parents, may consist of a mixture of the two forms.

What Gusella et al. described two years ago was the identification of the site of a restriction fragment length polymorphism, somewhere on chromosome 4 in human beings, which appears to be closely linked in its inheritance with the gene responsible for Huntington's chorea, whatever that may be. But the polymorphism and the gene are some way apart from each other. Gusella and his colleagues were at pains to insist, in their account of their work, that their "probe", a piece of DNA spanning the variable restriction site, should not, for the time being, be used as a diagnostic test for the disease. Plainly, there is a chance that the restriction site and the gene will not be inseparably tied together in inheritance, and until there are probes for sites closer to, or on either side of, the putative gene, there will always be a possibility of false diagnosis. There is, moreover, still the possibility that some families with Huntington's disease will prove to have a completely different genetic defect.

This is the basis on which Gusella has so far declined to provide the structure of his group's probe to the Oxford group, which says that it wishes to "apply DNA techniques to the practical problems presented by patients and their relatives". The need is easily imagined. Huntington's chorea is perhaps the most haunting of inherited diseases. Throughout early life and especially during many procreative years, patients will be free of symptoms. But then they are afflicted with neurological deterioration which is invariably fatal. The Oxford group is bent on genetic counselling among the relatives of cryptic victims of the disease, which would entail that many unknowing future patients should be told of their condition. Gusella says that this will remain unethical so long as the diagnosis is less than certain. He is concerned above all with the plight of the false positives, those who may carry a restriction fragment length polymorphism characteristic (for the family concerned) of Huntington's chorea.
On this narrow issue, Gusella may be over-squeamish. People belonging to families in which Huntington's is rife are probably already painfully aware of the risks to themselves and their children. These may well be the circumstances in which firmer knowledge, however much more painful, is preferably to gnawing anxiety. But one such as Gusella, who has at his disposal a material that may be of value in the diagnosis of a genetic disease, would be well within his rights to require a full explanation of the programme of investigations that others wish to undertake with his material. Indeed, it would be irresponsible to do otherwise.

This points to a more general issue, that of the obligations of researchers to others wishing to obtain samples of research material. It is well within the rights of a researcher in such a position to demand a full account of the purposes for which the material is required. Mere curiosity is an insufficient basis for a request. The possibility that research material might be used for commercial purposes is also a sufficient reason why a researcher might decline to provide it on demand. This shows that the obligation of a researcher to provide research materials cannot be absolute.

There are other circumstances in which refusal cannot be justified. Researchers have a legitimate right to verify what their colleagues and even competitors claim to have done. Artificial restrictions, such as the suggestion that verification should be carried out in the original laboratory, are only occasionally justifiable (as on safety grounds). Even allowing that the provision of research materials may help a competitor to get ahead should not be grounds for refusal. The principle that discoveries are common property is widely acknowledged but not always gracefully accepted.

Nature has not so far followed some other journals in making an undertaking to supply research materials a condition of publication because of difficulties such as that to which Gusella refers. But its interest, like that of the scientific community as a whole, lies in that direction. A promise that research materials will be made available to others will not be a firm condition of publication, but the presumption that reasonable requests will be met will remain an ingredient of polite correspondence with would-be authors.

John Maddox 